\title{
On Construction of Competency Evaluation Model of Knowledge Workers in High-tech Enterprises
}

\author{
Dexiang Yang \\ College of Management Science, Chengdu University of Technology, Chengdu, Sichuan, \\ China
}

email.26742678@qq.com

\begin{abstract}
Key words: comprehensive ability, evaluation model, knowledge type, competency evaluation, fuzzy comprehensive evaluation.
\end{abstract}

\begin{abstract}
This paper, based on the theory and method of competency model of knowledge workers' comprehensive ability, creates the competency model of knowledge workers in high tech enterprises so as to provide a scientific and theoretical basis for the training, selection, evaluation of competent talents. Targeted on those knowledge-oriented workers in high-tech enterprises, this paper will elaborate the knowledge workers' competency model on the bases of interviewing key event, questionnaire and statistical analysis. Furthermore, multi factor line regression model will be explained with the analysis of first class fuzzy comprehensive evaluation and second class fuzzy comprehensive evaluation as a premise. Competency model is a guideline in the recruitment, selection of knowledge workers, motivating, and training and performance evaluation in high tech enterprises. It will also be a lighthouse of the self-development of the knowledge workers.
\end{abstract}

\section{Introduction}

Core competitiveness is the basis for a sustainable development of a high-tech enterprise and the fundamental force for high-tech enterprises to achieve their strategic development goals [1-3]. Once defined the strategic objectives, a high-tech enterprise still needs the correspondent core competitiveness as the auxiliary. As the hi-tech enterprise knowledge-based employees are the primary resources of the enterprise and the key element for forming the core competitiveness [4]. Hierarchical decomposition of the core competitiveness of high-tech companies will eventually displayed on employees' comprehensive capabilities [5-7]. Therefore, if a high-tech enterprise wants to cultivate core competences, it should require the employees have appropriate levels of competency or core skills, including knowledge, skills, behaviors, internal drives, and personality trends [8]. That is, the key to influencing the formation of core competitiveness is the level of competency of the employees, which in turn has a corresponding impact on the achievement of corporate business strategic goals. This is closely related to the sustainable development of the company. [9-11]

The establishment of competency model is a necessary. And it is also the focus of management research in recent years. It can provide scientific basis for the selection, evaluation, training and motivation of employees. This paper uses the competency model method and theory to build the competency model of knowledge workers in high-tech enterprises, which in return will provide scientific and rigorous theoretical basis for the selection and performance assessment of knowledge workers.

\section{Theories}

The competence refers to the characteristics that can be measured by objective conditions that are superior to ordinary people in certain work positions and organizational environments. The competency model is, by using of behavior event method, to extract a set of factors that a promised person needs in a certain position, including different personality, motivation, quality requirements, social roles, self-image characteristics, skill level, knowledge level, etc. Combine the factors together, then prioritize those factors, and finally come into the theory. Knowledge workers are 
those who can apply expert system to increase their value. Scholars have conducted many theoretical and practical studies on the concept of knowledge workers. Tu Haiqun [12] (2004) studied the classification of knowledge workers. Liao Jianqiao [13] (2009) divided the knowledge workers into several types, mainly on three dimensions: the dimension of application, creation and dissemination.

Each dimension is divided into two zones, namely the high and low. Combined all possibilities, knowledge workers can be divided into eight types. Yu Fei [14] (2011) took knowledge workers, conducted in-depth and practical research on high-tech enterprises through questionnaires, interviews, and mathematical statistics analysis of key events, and built a competency mode. The model guides the recruitment, selection of knowledge workers, motivating, and training and performance evaluation in high tech enterprises. It will also be a lighthouse of the self-development of the knowledge workers. Qun Qun[15] (2011) adopted a comprehensive evaluation method and combined fuzzy mathematics with analytic hierarchy process to evaluate and study the competence level of knowledge workers, and provide enterprises with new ideas for better management of knowledge workers. Huang Ming [16] (2016) analyzed the causes of competency and developed a competency model for cultural and creative talents. The construction of competency is comprehensively assessed on the corporate strategic objectives, evaluation indicators, capabilities of assessors, value of assessment and assessment methodology.

\section{Researches}

Here, it is necessary to analyze the industry and business characteristics of high-tech companies, sample testing of some companies so as to fully understand the performance of existing employees, work conditions and composition, their management methods. According to the different requirements of each position in the sample companies, one or two employees are selected from the competent workers and ordinary workers. The key event interview method and is adapted to record relevant data and information, to analyze the result of interviewing senior managers and experts. Also, it will discuss the key behavior and core competency of knowledge workers, obtain sample information about knowledge workers' comprehensive capabilities. Together with the existing position performance standards, job descriptions, and other documents, competency questionnaires is compiled and carried out in the selected enterprises. Finally, a detailed analysis of the result of the questionnaire was conducted to determine the competency model of knowledge workers in high-tech enterprises.

According to the competency characteristics extracted from the result of interviews of key events, it will tentatively describe and transfer each competency characteristics to come out 40 descriptive behavior questions. The questionnaire, which also describes the competency by behavior, then assigns the indicator elements according to the importance, 1 point for least important, least important $<2$ points $<$ less important, less important 3 points, less important $<4$ points $<$ important, important 5 points and 6 for very important. Out of 450 questionnaires distributed, 410 valid questionnaires were eventually collected.

\section{Construction of Knowledge Worker Competency Model}

\subsection{Construction of Evaluation Index System for Knowledge Worker Competency}

Statistical analysis Tool SPSS19.0 was used to analyze the 410 valid questionnaires, resulting the main factors affecting the comprehensive ability of knowledge workers are knowledge, skills, abilities, personality and motivation. In accordance with the competencies of each factor, these four competencies are named as follows: Knowledge dimension B1: Competent for existing work, knowing of various professional knowledge and general knowledge required. Skills dimension B2: competent of current work and master of the business. Ability dimension B3: All thoughts and actions related to innovation, planning, and induction can be utilized to analyze the problem, understand the problem, and solve the problem, live alone with all colleagues and handle different 
things. Personality and Motivation Dimension B4: This includes the basic characteristics and basic qualities of a person, as well as personality, quality, values, social motivation, internal driving force, attitude, and personal self-image etc. And way used in solving stress, encountering emergencies, and solving problems will significantly reflect the competency. This paper is based on the four dimensions and the result is shown in Figure 1.

Table 1 Knowledge Worker Competencies Index System Tab 1 Competency evaluation index system of knowledge workers

\begin{tabular}{|c|c|c|c|}
\hline \multicolumn{3}{|c|}{ Level } & \multirow[b]{2}{*}{ Conception } \\
\hline $\begin{array}{l}\text { First } \\
\text { Level }\end{array}$ & $\begin{array}{l}\text { Second } \\
\text { Level }\end{array}$ & $\begin{array}{l}\text { Third } \\
\text { Level }\end{array}$ & \\
\hline \multirow[t]{15}{*}{ C_A } & B1 & $\begin{array}{l}\text { Education background } \\
\text { C11 }\end{array}$ & Education Experience \\
\hline & & Work experience $\mathrm{C} 12$ & $\begin{array}{l}\text { Work experience aggregated based on training, } \\
\text { developing and working time }\end{array}$ \\
\hline & & $\begin{array}{l}\text { Professional Knowledge } \\
\text { of Exist Position }\end{array}$ & $\begin{array}{c}\text { Utilization of professional knowledge to carry } \\
\text { out the job }\end{array}$ \\
\hline & $\mathrm{B} 2$ & $\begin{array}{l}\text { Operation Skill of Exist } \\
\text { Position }\end{array}$ & $\begin{array}{l}\text { Operation skill pertained to implement the } \\
\text { work }\end{array}$ \\
\hline & & $\begin{array}{l}\text { Technology \& Innovation } \\
\text { C22 }\end{array}$ & $\begin{array}{l}\text { Proactively try to use the latest science } \\
\text { technology to improve the efficiency }\end{array}$ \\
\hline & B3 & $\begin{array}{l}\text { Communication Skill } \\
\text { C31 }\end{array}$ & Communication skill \\
\hline & & $\begin{array}{l}\text { Leadership } \\
\text { C32 }\end{array}$ & $\begin{array}{c}\text { Decision-making, organizational capability } \\
\text { and Ability to use talents }\end{array}$ \\
\hline & & $\begin{array}{l}\text { Learning Ability } \\
\text { C33 }\end{array}$ & Self-improvement by learning different things \\
\hline & & $\begin{array}{l}\text { Ability to resolve } \\
\text { Problems C34 }\end{array}$ & Proper way to resolve problem \\
\hline & & $\begin{array}{l}\text { Anti-pressure Ability } \\
\qquad \mathrm{C}_{35}\end{array}$ & Anti-pressure ability \\
\hline & & $\begin{array}{l}\text { Logic Thinking } \\
\quad \text { C36 }\end{array}$ & $\begin{array}{l}\text { The ability to compare, observe, analyze, } \\
\text { deduct and judge all things }\end{array}$ \\
\hline & \multirow[t]{4}{*}{ B4 } & $\begin{array}{l}\text { Team Work } \\
\text { C41 }\end{array}$ & $\begin{array}{l}\text { Team working and Cooperation with team } \\
\text { members }\end{array}$ \\
\hline & & $\begin{array}{l}\text { Achievement Orientation } \\
\text { C42 }\end{array}$ & $\begin{array}{l}\text { Set work target and KPI to achieve } \\
\text { self-improvement }\end{array}$ \\
\hline & & $\begin{array}{c}\text { Responsibility } \\
\text { C43 }\end{array}$ & Strong sense of responsibility to work \\
\hline & & $\begin{array}{l}\text { Professional Ethic } \\
\text { C44 }\end{array}$ & Love and full of passion to the work \\
\hline
\end{tabular}

\subsection{Comment Set}

Comment Set: $U=\left(u_{1}, u_{2}, \cdots, u_{n}\right)$, This Research: $\mathrm{U}=$ (Good, Better, Middle, Worse, Worst)

\subsection{Weight of the Indicators}

For each indicator, according to the expert group's score on the relative importance, the built and comparison of the judgment matrix is performed. It is assumed that the 12 experts have the same utility and prestige.

\subsubsection{Single Hierarchy Arrangement and its Consistency Check}

Formula (1) is to have single hierarchy arrangement and its consistency check:

$$
W_{i}=\frac{M_{i}}{\sum_{i=1}^{n} M_{i}}(i=1,2, \cdots, n), \quad M_{i}=\sqrt[n]{\prod_{j=1}^{n} c_{i j}}
$$


Formula (1) results that $W=\left\{W_{1}, W_{2}, \cdots, W_{n}\right\}^{T}$. It shows the most significant character of the judgement matrix: $\lambda_{\max }=\frac{1}{n} \sum_{i=1}^{n} \frac{(C W)_{i}}{W_{i}}$. At the same time, it checks the Consistent Index: C.I. $=\frac{\lambda_{\max }-n}{n-1}$. When C.I. $=0$, judgement matrix is absolutely the same. When random consistency rate $C . R .=\frac{C . I .}{R . I .}<0.1$, judgement matrix consistency is ideal. When $C . R .=\frac{C . I .}{R . I .}>0.1$, the matrix needs to be adjusted until it reaches the proper consistency value.

4.3.2 Total taxis of Hierarchy and its Consistency check

Same like the steps of single hierarchy arrangement, total taxis of hierarchy is also has the same check of single hierarchy arrangement. When getting the first level index weight $W=\left(W_{1}, W_{2}, \cdots, W_{n}\right)$, Then $W_{i}=\left(W_{i 1}, W_{i 2}, \cdots, W_{i j}\right)$ is second level index weight.

YAAHP0.5.2 will compare the judgement matrix and confirm the index related to competencies. On consistency rate $C . R .=\frac{C . I .}{R . I .}<0.1$, the $1^{\text {st }}$ level index weight and $2^{\text {nd }}$ level index weight in $1^{\text {st }}$ level index will be get from the matrix, which is shown in (2) (6) :

$$
\begin{gathered}
W=(0.1216,0.2450,0.3478,0.2847) \\
W_{1}=(0.2631,0.5479,0.1884) \\
W_{2}=(0.5496,0.4500) \\
W_{3}=(0.2492,0.1196,0.1846,0.1322,0.1461,0.1670) \\
W_{4}=(0.5186,0.2107,0.1484,0.1215)
\end{gathered}
$$

\subsection{Fuzzy Evaluation Matrix}

Membership grade is used to describe the degree of membership in the remark set, getting (7) the single factor fuzzy evaluation matrix $\mathrm{Ai}$ :

$$
A_{i}=\left[\begin{array}{cccc}
R_{11}^{i} & R_{12}^{i} & \cdots & R_{1 n}^{i} \\
R_{21}^{i} & R_{22}^{i} & \cdots & R_{2 n}^{i} \\
\cdots & \cdots & \cdots & \cdots \\
R_{k 1}^{i} & R_{k 2}^{i} & \cdots & R_{k n}^{i}
\end{array}\right] \quad i=(1,2, \cdots, m)
$$

Among the $3^{\text {rd }}$ level index in 1 and the $2^{\text {nd }}$ index in $\mathrm{i}$, it will use $a_{i j}^{i}$ to show that it subjects to $\mathrm{j}$ remark level. For example, the 12 experts, after evaluation, will come 2 results for one selected knowledge workers.

Table 2 Expert Panel's Remark on the Competency of Knowledge Worker A

\begin{tabular}{ccccccc}
\hline & Level & Good & Better & Middle & Worse & Worst \\
\hline \multirow{3}{*}{ B1 } & $\begin{array}{c}\text { Education background C11 } \\
\text { Work experience C12 }\end{array}$ & 4 & 4 & 0 & 0 & 0 \\
& $\begin{array}{c}\text { Professional knowledge on } \\
\text { current position C12 }\end{array}$ & 2 & 3 & 0 & 0 & 0 \\
& Operation skill on current & 3 & 2 & 3 & 1 & 0 \\
position C21 & & & 3 & 2 & 0 \\
\hline \multirow{3}{*}{ B2 } & Technology \& Innovation & 1 & 2 & 2 & 3 & 2 \\
& C22 & 5 & 2 & 2 & 1 & 0 \\
& Communication Skill C31 & 2 & 4 & 3 & 1 & 0 \\
Leadership C32 & Learning capability C33 & 4 & 4 & 2 & 0 & 0 \\
& Ability on Trouble shooting & 3 & 4 & 2 & 1 & 0 \\
& C34 & & & & &
\end{tabular}




\begin{tabular}{|c|c|c|c|c|c|c|}
\hline & $\begin{array}{l}\text { Ability to undertake } \\
\text { Pressure C35 }\end{array}$ & 3 & 3 & 2 & 2 & 0 \\
\hline & $\begin{array}{l}\text { Ability on Logic Thinking } \\
\text { C36 }\end{array}$ & 5 & 3 & 1 & 1 & 0 \\
\hline \multirow{4}{*}{$\mathrm{B}_{4}$} & Team Work C41 & 3 & 2 & 4 & 1 & 0 \\
\hline & Achievement Guideline C42 & 3 & 3 & 4 & 0 & 0 \\
\hline & Sense of Responsibility C43 & 3 & 1 & 4 & 1 & 0 \\
\hline & Professional Ethic C44 & 5 & 3 & 1 & 0 & 0 \\
\hline
\end{tabular}

As is shown in table 2 the assessment on competency, A1 is the knowledge workers' knowledge-relative matrix, A2 Skill matrix, A3 Capabilities Matrix and A4 motivation and personality matrix.

$$
\begin{aligned}
A_{1} & =\left[\begin{array}{lllll}
0.4 & 0.4 & 0 & 0 & 0 \\
0.5 & 0.3 & 0 & 0 & 0 \\
0.2 & 0.3 & 0.3 & 0.2 & 0
\end{array}\right] \\
A_{2} & =\left[\begin{array}{lllll}
0.3 & 0.2 & 0.3 & 0.1 & 0 \\
0.1 & 0.2 & 0.2 & 0.3 & 0.2
\end{array}\right] \\
A_{3} & =\left[\begin{array}{lllll}
0.4 & 0.2 & 0.2 & 0.1 & 0 \\
0.2 & 0.4 & 0.3 & 0.1 & 0 \\
0.4 & 0.4 & 0.2 & 0 & 0 \\
0.3 & 0.4 & 0.2 & 0.1 & 0 \\
0.3 & 0.3 & 0.2 & 0.2 & 0 \\
0.4 & 0.3 & 0.1 & 0.1 & 0
\end{array}\right] \\
A_{4} & =\left[\begin{array}{lllll}
0.3 & 0.2 & 0.4 & 0.1 & 0 \\
0.3 & 0.3 & 0.4 & 0 & 0 \\
0.3 & 0.1 & 0.4 & 0.1 & 0 \\
0.5 & 0.3 & 0.1 & 0 & 0
\end{array}\right]
\end{aligned}
$$

\subsection{Comprehensive Evaluation on First Level Fuzzy}

Operator will comprehensively evaluate the $1^{\text {st }}$ level fuzziness and confirm the relative fuzzy matrix $R=\left(R_{1}, R_{2}, \cdots, R_{n}\right)^{T}$, Show in (8):

$$
R_{i}=\left(W_{1}^{i}, W_{2}^{i}, \cdots, W_{k}^{i}\left[\begin{array}{cccc}
R_{11}^{i} & R_{12}^{i} & \cdots & R_{1 n}^{i} \\
R_{21}^{i} & R_{22}^{i} & \cdots & R_{2 n}^{i} \\
\cdots & \cdots & \cdots & \cdots \\
R_{k 1}^{i} & R_{k 2}^{i} & \cdots & R_{k n}^{i}
\end{array}\right]\right.
$$

Take knowledge worker $A$ as an example, the $1^{\text {st }}$ level fuzzy relation matrix $R_{1} 、 R_{2} 、 R_{3} 、 R_{4}$ :

$$
\begin{gathered}
R_{1}=W_{1} \cdot A_{1}=(0.5265,0.3788,0.0564,0.0375,0) \\
R_{2}=W_{2} \cdot A_{2}=(0.20,0.18,0.30,0.17,0.08) \\
R_{3}=W_{3} \cdot A_{3}=(0.37,0.3185,0.1950,0.0960,0) \\
R_{4}=W_{4} \cdot A_{4}=(0.3363,0.2182,0.3782,0.0665,0)
\end{gathered}
$$

\subsection{Comprehensive Evaluation on Second Level Fuzzy}

Confirm knowledge worker A's final result and confirm its $2^{\text {nd }}$ level fuzziness, shown in formula (9) 


$$
E=W \cdot R=\left(W_{1}, W_{2}, \cdots, W_{k}\right)\left[\begin{array}{cccc}
R_{11} & R_{12} & \cdots & R_{1 n} \\
R_{21} & R_{22} & \cdots & R_{2 n} \\
\cdots & \cdots & \cdots & \cdots \\
R_{k 1} & R_{k 2} & \cdots & R_{k n}
\end{array}\right]
$$

Exemplified by knowledge worker A: $\quad E_{A}=W \cdot R_{A}=(0.3470,0.2682,0.2585,0.01034,0.0220)$

\section{Creation of Competency Line Regression Model}

\subsection{Multi Line Regression Model}

Based on Fuzzy evaluation matrix, this paper analyzed 40 interviewees' comprehensive ability. And the multi live regression model is created based on the $1^{\text {st }}$ level fuzzy evaluation and $2^{\text {nd }}$ level fuzzy evaluation (Shown in table 3 ).

Tab 3 Results of performance analysis of 40 respondents

\begin{tabular}{|c|c|c|c|c|c|}
\hline Interviewee No\# & $\mathrm{F}_{1}$ & $\mathrm{~F}_{2}$ & $\mathrm{~F}_{3}$ & $\mathrm{~F}_{4}$ & $\begin{array}{c}\text { Performance } \\
\text { Secore }\end{array}$ \\
\hline 1 & -0.13000 & 2.03910 & 0.04933 & -0.66379 & 183 \\
\hline 2 & -0.64456 & 0.20652 & 1.65460 & 0.68814 & 183 \\
\hline 3 & 1.61840 & 1.36966 & -1.18324 & -0.17510 & 208 \\
\hline 4 & -0.04091 & -2.14287 & 0.07261 & 0.03362 & 123 \\
\hline 5 & -2.22026 & 1.48320 & 1.69036 & 0.84765 & 150 \\
\hline 6 & 1.05962 & -0.50167 & 1.92553 & 0.07676 & 208 \\
\hline 7 & -0.86773 & -0.00667 & -0.72797 & -0.94383 & 119 \\
\hline 8 & -0.35930 & -0.48457 & -2.17550 & -0.98604 & 98 \\
\hline 9 & 0.84811 & 1.01494 & 1.10340 & 1.03653 & 233 \\
\hline 10 & -0.03767 & -0.11100 & -0.16750 & 0.09995 & 158 \\
\hline 11 & 2.42993 & -1.31560 & -0.25655 & -2.3440 & 163 \\
\hline 12 & 0.65270 & -0.43000 & -0.79870 & 0.27850 & 163 \\
\hline 13 & 0.22787 & -0.04276 & -0.13965 & -0.67240 & 158 \\
\hline 14 & 1.03101 & -0.33362 & -0.50017 & 0.12497 & 179 \\
\hline 15 & -1.51080 & -2.30136 & 2.93512 & -2.02287 & 99 \\
\hline 16 & 1.05962 & -0.50167 & 1.92553 & 0.07676 & 208 \\
\hline 17 & -0.76530 & -1.84800 & -1.43196 & 0.88422 & 103 \\
\hline 18 & -1.86902 & 0.11500 & 0.05166 & -0.26461 & 113 \\
\hline 19 & -1.72500 & 0.83260 & -0.38601 & -0.32884 & 123 \\
\hline 20 & 1.38482 & -0.87421 & 0.25137 & 1.28884 & 203 \\
\hline 21 & -0.53062 & 0.15625 & 0.23400 & -0.46493 & 148 \\
\hline 22 & 0.45437 & -0.46580 & 0.45727 & -0.08715 & 173 \\
\hline 23 & -0.00074 & 0.17141 & -0.09655 & -0.44384 & 158 \\
\hline 24 & 0.51875 & 0.06305 & -0.55434 & 1.70610 & 193 \\
\hline 25 & -0.65010 & 1.32192 & -0.69210 & 0.16805 & 163 \\
\hline 26 & -0.83400 & 0.71131 & -0.94911 & -0.64700 & 129 \\
\hline 27 & -0.74672 & -1.08175 & -1.02144 & 0.53753 & 119 \\
\hline 28 & -0.59335 & 0.33827 & -0.06500 & -0.27095 & 148 \\
\hline 29 & -0.71173 & -1.52201 & -0.02757 & 3.04061 & 158 \\
\hline 30 & 0.60616 & -0.64274 & -0.50470 & -1.46754 & 138 \\
\hline 31 & -0.00073 & 0.17141 & -0.09655 & -0.44384 & 158 \\
\hline 32 & 0.10662 & 0.11504 & -1.31082 & -0.36505 & 143 \\
\hline 33 & 0.35214 & 0.44960 & 0.91015 & -0.90672 & 183 \\
\hline 34 & 0.67303 & 2.04181 & 0.24557 & -0.33610 & 213 \\
\hline 35 & -1.82825 & -0.30540 & -0.74568 & 0.07297 & 98 \\
\hline 36 & -0.00074 & 0.17142 & -0.09655 & -0.44384 & 158 \\
\hline 37 & 0.84504 & 1.70953 & 1.09146 & 0.29283 & 233 \\
\hline 38 & 0.53307 & -0.1874 & -0.14931 & 2.07010 & 199 \\
\hline 39 & 0.18367 & 0.19198 & -0.65510 & 0.51620 & 168 \\
\hline 40 & 0.13383 & 0.16542 & -0.10084 & -0.39331 & 163 \\
\hline
\end{tabular}




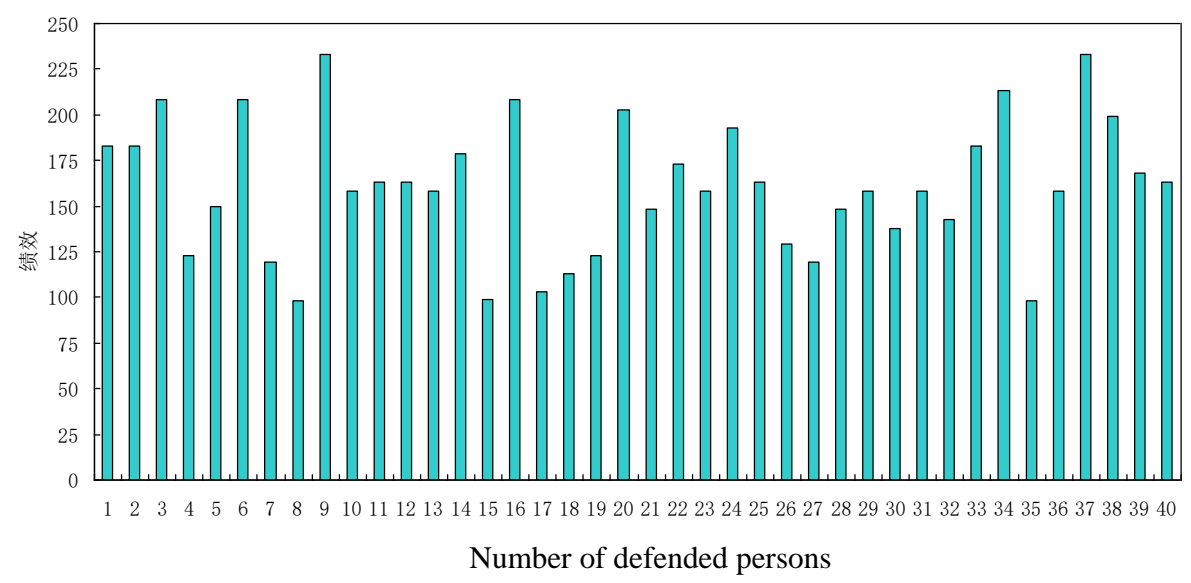

Fig 1 A comparison of the performance of 40 respondents

According to data in table 3 and regression analysis, the following competency line regression model is shown in formula (10):

$$
Y=160.403+33.652 F_{1}+12.047 F_{2}+8.175 F_{3}+10.641 F_{4}
$$

$\mathrm{Y}$ is interviewee's performance, F1 is comprehensive capabilities, F2 is initiatives capability and F4 is communication skill.

\subsection{Finalize Evaluation Level}

According to membership grade ( $\max$ ) principle, it is necessary to evaluate and finalize interviewee's level. Based on principles in Fuzziness, if $\max \left(e_{1}, e_{2}, \cdots, e_{k}, \cdots, e_{n}\right)=e_{k}, \mathrm{k}$ is the result of interviewee. Then the result of that worker's competency is $(0.3470,0.2682,0.2586,0.1035,0.0220)$, showing that the worker has excellent marks on competency.

After the calculation, if the two employees have the same rating, then the comprehensive score of the competency level should be calculated. For example, when a fuzzy comprehensive evaluation of another knowledge worker has the same rating level, there will be a concrete comparison of the two competencies. This article gives a certain score to the rating level, multiplies this score with the corresponding rating value, and then sums its result to obtain a comprehensive score. Table 4 shows the corresponding scores for comment grades.

Tab 4 Rating scale

\begin{tabular}{cccccc}
\hline Rating level & Good & Better & Middle & Worse & Worst \\
\hline Score & 5 & 4 & 3 & 2 & 1 \\
\hline
\end{tabular}

Worker A's comprehensive competency shows in formula (11) :

$0.3470 \times 5+0.2682 \times 4+0.2586 \times 3+0.1035 \times 2+0.0220 \times 1=3.8126$

Worker B's comprehensive competency shows in formula (11) :

$0.3467 \times 5+0.2920 \times 4+0.2508 \times 3+0.0913 \times 2+0.0184 \times 1=3.8549$

From the calculation, we can know that for the score of the competencies of employee A is lower than the score of employee B. Therefore, A's competency is lower than that of $\mathrm{B}$, that is, $\mathrm{A}<\mathrm{B}$.

\section{Factors of generating Knowledge Workers Competency Test Model}

Through the above analysis, for high-tech enterprise knowledge workers, there should be four comprehensive competencies, namely, communication ability, team cooperation ability, initiative ability and professional comprehensive ability.

\subsection{Professional Ability}

It includes rational thinking, desire for accomplishment, learning ability, innovation ability, technical ability, and adaptability. In high-tech enterprises, the professional comprehensive ability is 
the core ability that a knowledge worker should have and of crucial importance to the performance. The above analysis shows that the professional comprehensive ability contributes the most to the overall contribution rate and can play a decisive role. This ability includes the ability to continuously innovate at work, the ability to adapt to complex work, the ability to learn to achieve self-achievement, solid professional skills, and rational thinking skills. The key to improving the skills of a knowledge worker is resilience and continuously learning ability. And, the key to the company's development is innovation. Through self-improvement, employees could dramatically increase the comprehensive level of high-tech enterprise to a new high.

\subsection{Initiative Ability}

In high-tech enterprises, it mainly refers to flexibility, self-confidence, initiative, and coordination ability, which are often referred to as invisible qualities and are not easy to evaluate and observe. These are often the key factors that hinder the development of enterprises and restrict employees themselves. Usually, excellent knowledge-based employees are confident, enthusiastic and active, and can handle and coordinate flexibly for a variety of unexpected problems. In the high-tech industry, there are still many technologies that have not been broken. Therefore, new issues will occur here and there, which requires knowledge-based work to be able to use professional skills and knowledge flexibly, and to actively take the initiative to handle the problems that happens, which is the best display of the competency of a knowledge worker.

\subsection{Teamwork Capability}

It mainly shows on adaptability, teamwork, and the sense of responsibility. As we all know, technology development is difficult to accomplish by one person. Team development is the most common model, which needs all kinds of coordination and cooperation. When dealing with a bid project, it will involve the entire company. Therefore, team work is very important. The relationship between the coordination team and the entire project, the relationship between the members, and the relationship between the teams are particularly important. In addition, the sense of responsibility is also crucial. The personal development goals and organizational development goals of the employees can be effectively combined through the sense of responsibility of the employees. The interests of the organization need to be prioritized, and the work must be performed with due diligence and inevitability.

\subsection{Communication Ability}

In high-tech enterprises, the communication skills of knowledge workers mainly include interpersonal insight, language expression, and communication skills, which is a necessary to obtain. In the work, through smooth communication, the errors caused by information transmission can be reduced, which ensures the efficiency of the work. For each employee at work, teamwork capabilities are important, so the ability to communicate is also critical. Good communication skills enable employees to communicate quickly, accurately and without barriers during work.

In summary, the relevant competency model of knowledge workers can be obtained and applied to human resources and many other industries.

\section{Application Instances}

This research will take S company as an example and will apply the competency model during its recruitment.

\subsection{Implementation Process of applying competency model in the recruitment of $S$ company}

The company needs to enroll a number of knowledge-based employees. After the preliminary screening on the skills, qualifications, and professional primaries of the all candidates, 4 win. Then interview the four primary candidates, using behavioral event interviews to interview the 4 candidates and build the competency model based on the interview result. And a linear regression model of competency and Table 6 were used to calculate and finally the newly-employed personnel 
were ranked in terms of expected performance. Table 5 is a list of the expected performance of new recruits. From the ranking table shown in Table 5, it can be seen that for the ranking of the hiring person, the new evaluation method is the same as the ranking after the evaluation according to the original evaluation standard, and the new evaluation method is more accurate and specific, which indicates that competency model provides a comprehensive distinction between the average performer and the meritorious performer. Based on the ranking, S company eventually hired the top 3 candidates, namely A1, A3 and A4 candidates.

Tab 5 Ranking of new recruits' expected performance

\begin{tabular}{ccccccc}
\hline $\begin{array}{c}\text { Candidates' } \\
\text { No. }\end{array}$ & $\mathrm{F}_{1}$ & $\mathrm{~F}_{2}$ & $\mathrm{~F}_{3}$ & $\mathrm{~F}_{4}$ & $\begin{array}{c}\text { Performa } \\
\text { nce }\end{array}$ & $\begin{array}{c}\text { Ranki } \\
\text { ng }\end{array}$ \\
\hline A1 & 9.870 & 10.174 & 8.203 & 7.613 & 763.9720 & 3 \\
A2 & 6.653 & 10.62 & 8.698 & 8.304 & 672.0131 & 4 \\
A3 & 10.583 & 8.550 & 10.358 & 9.618 & 806.9813 & 2 \\
A4 & 14.514 & 6.498 & 12.029 & 10.933 & 941.9496 & 1 \\
\hline
\end{tabular}

\subsection{Effectiveness Analysis of Competency Model in Recruitment}

After several months of trial implementation and improvement, the newly-built competency model of S company was gradually improved. In the recruitment of S company, the model was applied to the second interview. Therefore, the assessment index has a quantifiable feature and the model can be evaluated. The combination of the explicit quality of talents and potential qualities, the combination of quantitative assessment and qualitative assessment, and the accuracy of talents identification have been improved, as well as the talent management of S company.

\subsubsection{Combination of Interviewee's Potential and Explicit Competencies}

In the past, the company was only able to test talent's explicit quality, and its potential quality assessment was powerless. The competency model solved this problem very well, and it was able to evaluate candidates comprehensively and accurately. The performance has greatly improved. Also, the model provides the basis for employee's future promotion and training.

\subsubsection{Combination of Quality Assessment and Quantity Assessment}

The company organically compares the basic capabilities and competencies, and draws inadequacies and desirable points between each other. It also improves the accuracy of assessments when involving interview during talent selection.

\subsubsection{The Increase of Accuracy on Identifying Talents}

After using the evaluation system, the recognition rate of talents has been greatly improved in $S$ company. And the interviewers' limit experience during the interview will not affect the fairness of the recruitment. During the probation period, one employee was dismissed because he is incompetent of carrying out his job. One employee resigned. The other four knowledge workers managed to pass the internship period. "The overall quality of these four people is very high, the level of work and performance are also very good" said by the department heads who is very satisfied with their level of business.

\subsubsection{Significant Improvement of Talent Management of S Company}

Recruitment is a two-way selection process. Employers and candidates choose each other. Candidates can learn about the company's background during probation. They can feel the company's culture and management while they are closely connected. The most direct way to inspect the company's management level is to use the various aspects of the recruitment process to standardize the recruitment test. The link and testing system gives applicants a message that talents are well managed and are appreciated, which will attract more talents.

\section{Conclusions}

This paper adopts the theory and method of competency model theory to research the comprehensive ability of knowledge workers, builds a knowledge-based employee competency model among high-tech enterprises, and provides scientific and rigorous theoretical basis for 
selection and assessment of talents. Exemplifying with the research-based knowledge employees , in-depth research on high-tech companies conducted, and the utilization of key event interviews, questionnaires, mathematical statistics and other methods are all combined to build a research-based knowledge worker competency model. Together with $1^{\text {st }}$ level fuzzy comprehensive evaluation of the competency evaluation model and $2^{\text {nd }}$ level fuzzy comprehensive evaluation, a multiple linear regression model is also developed. The combination of the 2 methodology provide a basis for the selection, motivation, training, and performance evaluation of knowledge workers during the company's recruitment, and also guide the self-development of knowledge workers.

\section{The author's information}

Dexiang Yang, male, the Han nationality, hubei honghu, College of Management Science, Chengdu University of Technology, associate professor, $\mathrm{PhD}$, research direction in business management, human resource management.

Express address:College of Management Science, Chengdu University of Technology, 1\#, Dongsanlu, Erxianqiao, Chengdu, Sichuan, P.R. China.

E-mails: 26742678@qq.com

Tel:13980880155

\section{Acknowledgement}

The authors are grateful to the editor and anonymous reviewers for their insightful comments. This work was financially supported by the General Program of Mineral Resources Research Center in Sichuan Province (Grant no. SCKCZY2017-YB10, General Program of Chengdu University of Technology (Grant no. ZX1701-YB-017).

\section{References}

[1] Chen Yanxia.Research on the Construction and Application of Creative Talent's ability quality Model[D],Quanzhou: overseas Chinese University, 2011.

[2] Wu Jinwen, Ma Shaoqi, Zhang Minqiang, Xiang Ming, Zhang Jieting.Empirical Study on the Competency Quality Evaluation for Book Editors.Psychological Exploration.2013(6):544-548.

[3] Huang Ming.Construction of a Performance Management System:Based on Competency Model of Culture and Creative Industry Talents[J], Journal of Yichun College, 2015(4):52-57.

[4] Du Juan, Zhao Wan-ting.Competency-Based Talent Assessment System:Comparison Researchbetween Chinese and American Sales Managers[J], Journal of Beijing normal University: social Sciences Edition. 2011(5):130-135.

[5] Chen Huipin.Research on the Application of competency Model in evaluating the quality of salespeople[J],Market Modernization,2013(24): 137-13.

[6] Cai Fengyan.Exploration of competency Model for basic staff[J], Intelligence,2014,10:302.

[7] CHEN Youling, ZHU Ying, XIE Shuhong. Modern manufacturing unit staff knowledge capacity model and empirical study. Computer Engineering and Applications, 2016, 52 (8) : 243-249.

[8] Yang Hong-ying, Xu Yue-ming.Study on evaluation model of scientific personnel in stateowned enterprises based on the structure hierarchy[J], China Population, Resources and Environment ,2016,21(11):254-258.

[9] Huang Guo ,Geng Wei ,Jiang Yongqing. Researches on Personal Performance Valuation System Based on KPI Mode in Agricultural Research Institutions[J],Management of Agricultural 
Science and Technology,2012,31(6) :87-89.

[10]Zhang Yuzhu,Shu Haixia,Xu Wenzhong.The Evaluation,Promotion and Application of production skill personnel's Post ability based on training Standard[J],Technology and Economic Guide,2016,34:249-251.

[11]Tu Haiqun.Four Corresponding Relationship of Knowledge Worker ' s Motivation[J],Enterprise Reform and Management,2004,4:24-25.

[12]Liao Jianqiao,Wen Peng.Review of the Study on Definition, Characters and Classification of Knowledge Worker[J], Chinese Journal of Management,2009,6(2)277-283.

[13] Yu Fei.Construction of competency Model for Scientific Research knowledge Workers: a study based on High-tech Enterprises[J],China Management Informationization,2011,14(18):82-87.

[14]Qu Qunzhen,Huangfu Chengming.Research on competency Evaluation of Knowledge-based staff[J],Commercial Research,2011,11:140-144.

[15]Huang Ming.Competency Model for Culture Creative Talents'Evaluation-Selection System

[16][J],Journal of Hubei University of Arts and Science,2016,37(11):61-67. 